\title{
Rhetorics of the Visual: Graphic Medicine, Comics and its Affordances
}

\author{
Sathyaraj Venkatesan ${ }^{1} \&$ Sweetha Saji ${ }^{2}$ \\ ${ }^{1}$ Assistant Professor of English in the Department of Humanities at the National Institute of \\ Technology, Trichy, India. Email: sathya@nitt.edu \\ ${ }^{2}$ Research Scholar at the National Institute of Technology, Trichy, India. \\ Email: sweethasaji@gmail.com
}

Received June o8, 2016; Revised July 18, 2016; Accepted July 28, 2016; Published August 18, 2016

\begin{abstract}
Affordances, in the context of comics, connote to the general attributes of the medium such as temporality, spatiality, gestures, tone/handwriting and economy. Although comics evinces a dynamic relationship among these elements, it is possible to delineate functional and rhetorical role of these affordances on a conceptual and technical level. Taking these cues, the paper after briefly reviewing the definition and scope of graphic medicine aims to demonstrate the functional and rhetorical role of the aforementioned affordances in communicating illness and illness related experiences. Among other issues this article also seeks to address the following: how do comics engage in the visual and verbal translation of the experiences of chronic illness? how do affordances of comics facilitate the readers' haptic experience of an author's subjective trauma? Despite its juvenile legacy, comics capacitates graphic medicine to represent physical and emotional aspects of narrating subjective illness experiences within the medium. The paper concludes that comics is a uniquely suited communicative medium as it diagrams the interiority of illness experience, and, in the process, evolves itself as a locus of tacit knowledge through its translation and mediation of emotional truths and affective states altered by illness.
\end{abstract}

Keywords: graphic medicine, comics, affordances, spatio-temporality, gestures, handwriting

\section{Introduction}

Affordances, in the context of comics, connote to the general attributes of the medium such as temporality, spatiality, gestures, tone/handwriting and economy. Although comics evinces a dynamic relationship among these elements, it is possible to delineate functional and rhetorical role of these affordances on a conceptual and technical level. Taking these cues, the paper after briefly reviewing the definition and scope of graphic medicine aims to demonstrate the functional and rhetorical role of the aforementioned affordances in communicating illness and illness related experiences. Among other issues this article also seeks to address the following: how do comics engage in the visual and verbal translation of the experiences of chronic illness? how do affordances of comics facilitate the readers' haptic experience of an author's subjective trauma? Despite its juvenile legacy, comics capacitates graphic medicine to represent physical and emotional aspects of narrating subjective illness experiences within the medium. The paper concludes that comics is a uniquely suited communicative medium as it diagrams the interiority

(C) AesthetixMS 2016. This Open Access article is published under a Creative Commons Attribution Non-Commercial 4.o International License (http://creativecommons.org/licenses/by-nc/4.o/), which permits non-commercial re-use, distribution, and reproduction in any medium, provided the original work is properly cited. For citation use the DOI. For commercial re-use, please contact editor@rupkatha.com. 
of illness experience, and, in the process, evolves itself as a locus of tacit knowledge through its translation and mediation of emotional truths and affective states altered by illness.

\section{Graphic Medicine: Definition and Scope}

Before addressing the aforementioned issues, it would be instructive to examine the definition and scope of graphic medicine ${ }^{1}$. There has been over the past decade a burgeoning of a new breed of comics dealing with the patient experience of illness or caring for others with an illness. Christened as 'graphic medicine' by the British doctor and graphic novelist Ian Williams, these graphic illness narratives allude to "the intersection of the medium of comics and the discourse of health care" (Czerwiec, 2015, p. 1). Emphasizing the uniqueness of these narratives, Sathyaraj Venkatesan defines graphic medicine as "comics' distinctive engagement with and performance of illness experience" (2016, p. 93). Although these narratives are predominately autobiographical, they also address various socio-cultural issues impinging health care such as medical negligence; the vexed doctor-patient relationship; industrialism of health care; patient identity; role of insurance providers; challenges of caretaking; demands of being a doctor in a commercialized healthcare sector, among others.

Although as early as Justin Green's Binky Brown Meets the Holy Virgin Mary (1972) explores the mental torments of Obsessive Compulsive Disorder (OCD), it is Al Davison's The Spiral Cage (1990) and Harvey Pekar and Joyce Brabner's Our Cancer Year (1994) which launched graphic medicine definitively. Till then there has been a plethora of graphic medical narratives which deliberate on various illness experience ranging from AIDS to Asperger Syndrome narrated by doctors, professional caregivers or patients themselves. Prominent graphic medical narratives include Marisa Acocella Marchetto's autobiographical Cancer Vixen (breast cancer), Brain Fies's memoir Mom's Cancer (lung cancer), MK Czerwiec's Comic Nurse, Sarah Leavitt's Tangles (Alzheimer), Stan Mack's Janet and Me (breast cancer), among others. While the pedagogical role of comics within healthcare (a.k.a. education comics) has been acknowledged, these graphic illness narratives mostly from patient's perspective constitute a new form of knowledge which challenges mere medical and diagnostic approach of a disease.

\section{"Choreographing and Shaping Time": Spatio-temporal Dimensions of Comics}

Comparing comics with other media, McCloud contends thus, "[i]n every other form of narrative that I know of, past, present, and future are not shown simultaneously-you are always in the now. And future is something that you can anticipate, and the past is something you can remember. Comics is the only form in which, past, present, and future are visible simultaneously" (McCloud, 2007). Discerned as one of the seminal features of the comics, temporality allows the cartoonists to "choreograph and shape time" in immobile frames in that it juxtaposes past, present and imagined future within a single visual design (Spiegelman, 2005, p. 4). Lefevre exalts this dexterous palimpsesting of different temporalities on the same visual scheme as "multitemporality" (2011, p. 24). In the context of illness narrative, this juxtaposition of past, present and future in a single frame facilitates the diseased subjects to visually construct their lived body experience while mapping their traumatic progression from past to present. Especially in cases of chronic illnesses like AIDS and breast cancer, the sufferer's yearning for the past healthy body is often juxtaposed with the trauma and stigma of present sick body (usually in a single panel) to differentiate and identify their lived experience before and during/after the 
illness. In effect, spatio-temporal affordances of comics help the cartoonists to delineate "hybrid subjectivities" (Chute, 2010, p. 5) caused by illness.

Further reinforcing the faculty of comics, Lefevre's idea of "temporal flexibility" (2011, p. 24) denotes the stretching of a moment in time to reproduce varied vignettes of an experience. Acknowledging that there is no objective way to determine time encapsulated within a panel, Lefevre accents the flexibility of the comics medium in that it can disrupt the spatio-temporal conventions of traditional narrative which follows a linear succession of events. Attesting to the complex relationship between "the sequence of events happening (chronology) and the sequence in which they are narrated (narrative line)," Bredehoft argues that comics offers the possibility of a narrative mode that disrupts the uni-directional and irreversible nature of time. This twodimensional architecture of the comics page "allows comics narration to break the linearity of a time-sequenced narrative line" (2006, p. 872). It is this diversion from linearity coupled with the temporal flexibility that makes comics the preferred medium for narrating auto/biographical, historical, and illness experiences.

In fact, comics allows the author to recount memories experientially in narrative/subjective time sequence against the ideal of chronological/objective time and thus remains faithful to the experiences of the self. Invoking Henri Bergson's philosophy of clock time and subjective/psychic time, Elisabeth El Refaie differentiates between chronological and narrative time sequence in comics. Accordingly, distinct from clock time which consists of "abstract, homogenous, infinitely divisible segments," la durée or psychic time is a single indivisible temporal entity which is felt "intuitively, from our actual experience" (2012, p. 96). A segment in the clock time may reduce or extend according to an individual's actual experience of time. In case of trauma and illness this experience of time could be truthfully and authentically represented by stretching it across multiple panels. As the multiple self-portraits and avatars in illness narratives depict the yearnings and threats of a diseased body, spatio-temporality aids the cartoonist to suture various layers of a person's self which is fragmented by disease.

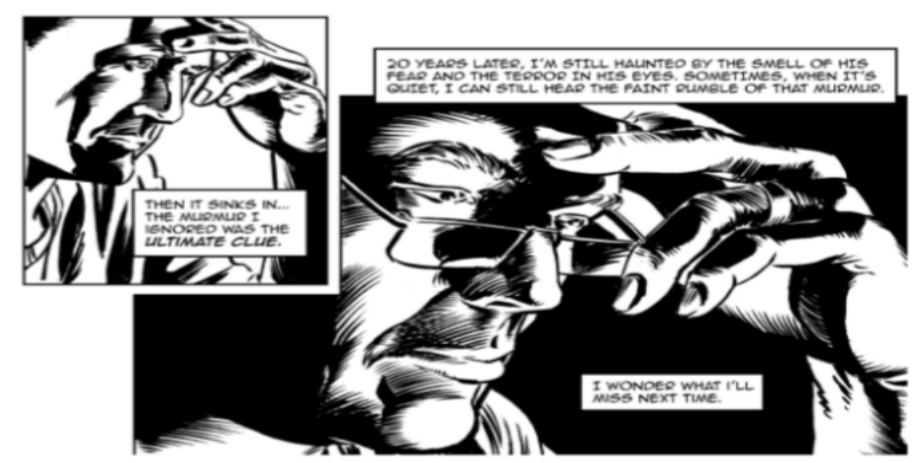

Figure 1. Panel from "Missed It.” (Green, 2013, p. 361).

For instance, Michael Green and Ray Reick's medical intern-narrative Missed It (2013) demonstrates the specific potentials of temporality. Green recollects in his five page comics a clinical error that he has committed during his internship and projects the lasting effects of traumatic guilt that haunts Green for years. Juxtaposing two panels that trace Green's transformation from an intern to a doctor, Missed It culminates with the image that palimpsests two phases of Green economically-the present self engaging major portion of the panel and the past self in the inset-both manifesting the same expression of regret over the clinical error (see fig. 1). In spite of the temporal distance of twenty years, the guilt in his eyes remains unaltered signifying the enduring effect of the past in the present. 
In a different vein, Marisa Acocella Marchetto's Cancer Vixen: A True Story recounts the author's cancer diagnosis in subjective time sequence. While the author reiterates the specific moment "10:12 am" (see fig. 2) in the caption she also in seriating panels narrates her subjective experience of trauma as being siphoned into a black hole (see fig.2). This surreal experience of illness trauma detailing Marisa's sense of shock and despair extends to pages as opposed to one second as per objective clock time. Elsewhere her subjective experience of time freezes for a moment as she retorts thus, "I was alone, afraid, frozen in time for an eternity in a vast expanse of nothingness, surrounded by dark matter" (Marchetto, 2006, p. 9). The subjective time which Marchetto converges and sedates in her narrative, as Miller reminds, is "cancer time" that pervades the everyday experience of time (2014, p. 219). Marchetto vindicates her savouring of each moment in cancer time as a veritable expression of her subjective experience of illness. As a matter of fact, it is the dexterous manipulation of comics medium's temporal flexibility which aids the artist to retrieve and translate her subjective experience of trauma in la durée/psychic time.
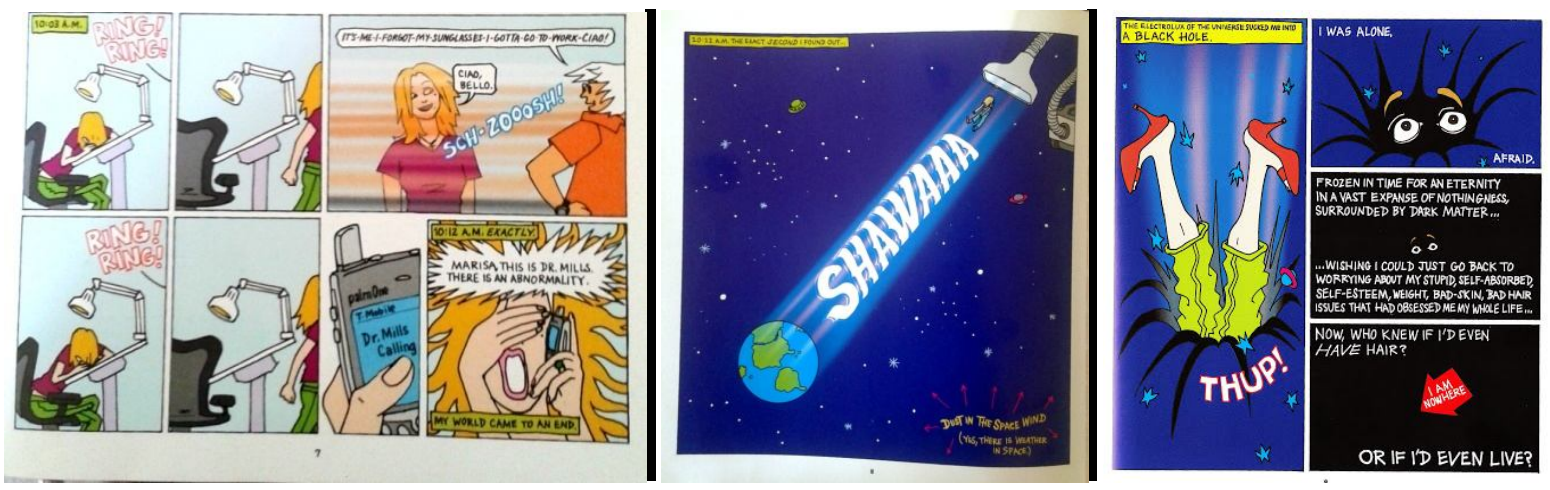

Figure 2. Panels depicting the "freezed" subjective time of the patient (Marchetto, 2oo6, p.7-9).

\section{Gutter Space and Closure}

Gutter, as Scott McCloud asserts, "plays host to much of the magic and mystery that are at the very heart of comics" by enabling "the human imagination [to synthesize] two separate images and transform[] them into a single idea" (1994, p. 66). Put differently, readers understand episodes of a comic story through the gutter space and by imagining the action that happens between the panels. This process of filling in by "observing the parts but perceiving the whole [is] called closure" (1994, p. 63). Closure in comics not only aids the readers to understand the narrative but also makes them an active collaborator in the process of making meaning. Moreover, the gutter stimulates time and motion between two panels as it performs a cross-panel function despite the space which separates them. Here the movement and experience are recreated in the gutter where the reader shares the author's creative vision in fragments of time.

Graphic pathographies trace bizarre shift in the routine and order of life caused by illness. Invoking the theoretical postulates of Heidegger, Carla Willig remarks how the experience of illness would remind one's own existence and mortality. Particularly in the case of chronic illness, one experiences unpleasant "throwness" "apparently without rhyme or reason, without warning or preparation, without explanation and without any choice in the matter" (2009, p. 182). Such traumatic conditions that constitute the illness experience is the major theme of pathographiesto quote Ann Hawkins, "[l]ife becomes filled with risk and danger as the ill person is transported out of the familiar everyday world into the realm of the body that no longer functions. . . life in all its myriad dimensions is reduced to a series of battles against death" (1999, p. 1). 
This rupture and disruption in the normal order of events parallels the intrinsically fragmented structure of comics. Otherwise stated, graphic medical narratives make use of the fragmented layout of comics contained in "boxes of time" (Chute, 2010, p. 6) in order to faithfully capture a patient's fractured sense of time and (corrupted) memory. Trauma is a "comparable liminal moment, which sharply demarcates a before and an after and which eludes both representation and interpretation" (Versluys, 2006, p. 986). In a conventional comics page layout, the gutter functions as a liminal space between the fractured pieces of traumatic memory wherein the reader sutures the disjointed "wounds" (Chaney, 2011, p. 5) and provides a desired closure. The closure thus achieved provides a textual completion and conclusion to trauma. Put differently, Versluys borrowing Huyssen's notion of "mimetic approximation" outlines how "traumatic experience [which] is inaccessible to language" (2006, p. 988) and characterized by a complete rupture of symbolic resources is mimetically approximated in the comics medium by the means of gutter space and layout. Although trauma resists exact representation, the comics medium induced by basic page structure and gutter space grants a mediated authentication which in turn enables the graphic pathographers to revive traumatic moments from the past and reconstitute the disrupted self out of its inherent meaninglessness.

In Billy, Me E You: A Memoir of Grief and Recovery, Nicola Streeten reconstructs the memories of Billy, her two year old son, his death and the subsequent trauma in her life. As the panels recollect and record the traumatic vignettes of the past, the reader seams the grief caused by untimely death and loss of the child by providing closure to the fragmented pieces of memory (see fig. 3). Though the time span between each panel extends to hours of sorrow and relief, the reader absorbs the intensity of trauma which saturates in the gutter space. In fact, the author and subsequently the reader participates in the mimetic approximation of a traumatic event and provide the much desired closure of the wound.

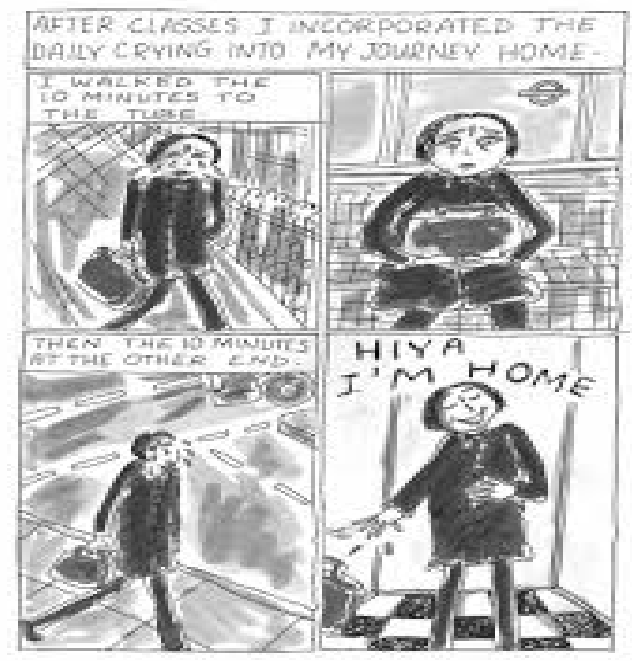

Figure 3. Billy, Me E You: A Memoir of Grief and Recovery. (Streeten, 2011, p. 11).

Illness apart from disrupting the biographical continuum fragments and sometimes corrupts the memory of a sick person. The intrincically fragmented structure of comics facilitates the artist to recount their episodes of trauma caused by illness. Michael Chaney in Graphic Subjects characterizes this as "a serial recuperation of trauma on a structural level. . . the way gutters (or wounds) separating one pictorial panel from another are routinely resolved in order to create meaning and coherence [through] . . c closure"' (2011, p. 5). In effect, the untranslatable trauma 
that the author leaves in the gutter space is transformed into an affective experience as the reader moves across the panels. Engaging the readers thus in the fragmented traumatic moments or experiences, "comics offer a window into the subjective realities of other sufferers and provide companionship through shared experience in a more immediate manner" than any other medium (Williams, 2012, p. 5).

\section{"Expressive anatomy": Gestures}

Identified as one of the seminal aspects of the comics medium, gestures embody human emotions and facilitate the effectual and eloquent narration of "internal feelings" (Eisner, 2008, p. 105) of the characters. Comics, as Squier attests, "direct our attention to the meaning conveyed by the body and its movements, gestures, and postures" (Czerweic, 2015, p. 49), and, in being so, it emerges as a performative and dynamic medium. As Berninger puts it in Comics as a Nexus of Cultures: Essays on the Interplay of Media, Disciplines and International Perspectives, comics is a "collection of gestures, complicated assemblages of bits and pieces which can be dissembled, labelled and examined carefully" (2010, p. 244). Depending on how well the readers relate to a certain image, gestures "invoke a nuance of emotion" to the character (Eisner, 2008, p. 106). Providing a leeway for the author to establish a visceral bond with the reader, gestures render immediacy by inviting the reader into the diegetic premises. As Eisner explains, "[i]n comics, body posture and gesture occupy a position of primacy over text. The manner in which these images are employed modifies and defines the intended meaning of the words" (2008, p. 106).

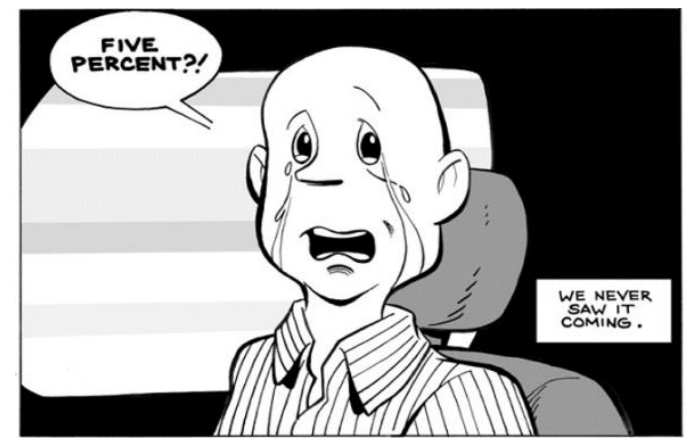

Figure 4. From Mom's Cancer (Fies, 2006, p. 94).

In graphic medical narratives, especially while depicting trauma, gestures accentuate ethereal emotions when pain erodes verbal language. Elaborating erasure/erosion of language caused by pain, Elaine Scarry contends thus, "[p]hysical pain does not simply resist language but actively destroys it, bringing about an immediate reversion to a state anterior to language, to the sounds and cries a human being makes before language is learned" (1985, p. 4). In kindred states of verbal deficit, comics through utilizing facial movements, eyebrows, eyes, eyelids, lips, jaws and cheeks "amplify meaning" and articulate the emotional aspect of human experiences that usually circumvent even the nuances of verbal language (Quesenberry, 2016, p. 77). Elsewhere Squier states thus, "[i]n their attention to human embodiment, and their combination of both words and gestures, comics can reveal unvoiced relationships, unarticulated emotions, unspoken possibilities, and even unacknowledged alternative perspectives (2008, p. 130). Stated otherwise, through its "expressive anatomy" , comics embodies subjective illness experiences and visualizes subtle unspeakable emotions thereby deepening the reader's involvement in the diegesis.

Fies' Mom's Cancer is an account of the author's mother, Barbara's struggle with metastatic lung cancer and her subsequent recovery from the same. Created in the latticed traditional format 
of comics, Mom's Cancer evinces how gestures facilitate the lucid expression of the inscrutable human emotions and trauma. Towards the end of her cancer treatment in chapter 32, titled 'The Five Percent Solution,' Fies pictures mom facing the readers with a melange of emotions as she realizes that only five percent of cancer patients survive the treatment. Mom absorbs this medical fact with horror, befuddlement and disbelief. For a moment Barbara becomes intensely fervid with conflicting emotions of contentment and trepidation. Accordingly, Mom's eyes are dilated with panic, tears overflowing, mouth agape with disbelief depicting illness trauma (see fig.4). Succinctly capturing the moment when language is eroded by emotional excess, the panel demonstrates the communicative faculty of gestures.

In a typical graphic medical narrative, the meaning and implications of medical treatment and illness experience is distilled through "movements, posture, and gestures of the body" and, in most cases, gestures take "precedence over the words in a text" (Squier, 2015, p. 49). In short, the incoherence, uncertainty, pain and other such extralinguistic phases of illness experience often assumes the form of gestures and body movements. Put differently, the inadequacy of verbal structures is leveled by "the alternative cognitive structures of the visual" (Hirsch, 2004, p. 1211). Gestures, which constitute the alternative structure, thus become inevitable for graphic pathographies in relaying human emotions and feelings of pain and trauma of illness.

\section{"The mark of its maker": Handwriting}

Comics medium engages with and concretizes the abstract subjective experience of illness also through lettering, coloring, and handwriting. Eisner asserts the pictorial quality of letters in Comics and Sequential Art thus, "[l]etters are symbols that are devised . . . out of familiar forms, objects, postures and other recognizable phenomena" (2008, p. 8). When an artist engages in the skillful manipulation of this "seemingly amorphous structure," she is in fact infusing her stories with deeper significance and relevance. In short, handwriting in its own terms provides comics a visual dimension.

In the context of graphic pathographies, handwriting through the marks/traces on the paper engages the reader to the realism of the text, accords immediacy to the narrative and also authenticates author's subjective experience. Although the rise of printing technology allowed experimenting with the typeface and color, Eisner contents that "[t]ypesetting does not have a kind of inherent authority" of the written expression (2008, p. 26). That said, unlike textual narratives, comics engages with the reader not only through the images but also through visual attributes of the word. Johanna Drucker while tracing the effect of print technology in relation to graphic novels associates handwritten language in comics and graphic novels with "voice, authorial enunciation, and character" (2008, p. 42). Handwriting is thus part of "extra-semantic information" that the reader receives making, in one sense, all graphic narratives "autographic" (Chute and Marianne DeKoven, 2006, p. 767). Unlike the experience of reading a verbal text, "the reader is urged to feel a more personal connection to the text" through the inclusion of handwriting and the varied styles of it (Cour, 2010, p. 52). Fredrich Kittler's distinction between the "private exteriority" of handwriting and the "anonymous exteriority" of the print also explains the reader's sense of immediacy to the author's experience (as cited in Cour, 2010, p. 52). Put differently, handwriting renders access to the subjective world of the author as against the objective quality of print.

Sarah Leavitt's Tangles: A Story About Alzheimer's, My Mother, and Me which mediates on the degenerative neurotic disease of Midge, her mother, deploys 'handwriting' as a visual tool to 
diagram the degradation of her mother from personhood to patienthood. Leavitt deploys handwriting as a reflection of the "cruel relentless progression of losses" (n.p) caused by alzheimer-as she herself admits thus, "[i]t took me a while to decipher her new handwriting" (2012, p. 40). Vaidehi Ramanathan's notion of identity erosion postulated as "meet[ing] their own absence" (2009, p. 78) finds a philosophical resonance in Midge's loss of linguistic identity. In a chapter titled "Diagnosis," Midge's transmuted personhood characterized by loss of linguistic competence and obliterated identity is traced through "new handwriting" (n.p) (see fig. 5).

In reproducing the handwritten letters/notes of her mother or the "tiny notes" (2012, p. 34) as Leavitt calls them, the author not only divulges the personal identity crisis and the loss of linguistic identity but also unravels the degeneration of Midge's cognitive and motor skills. Reflective of her deranged mind, Midge's struggle with herself is evident in her handwriting which resists the norms of writing neatly and without errors in a straight/linear line. Tangled with emotions, the handwriting as a technique of embodiment relays the angst of self-expression. Similarly, notes that are written and crossed out signify Midge's endless scuffle to appropriate to her prior self. Interestingly, beyond the aforementioned uses, handwriting as subjective mark of the creator is a strategic tool of the author to win the reader's trust.

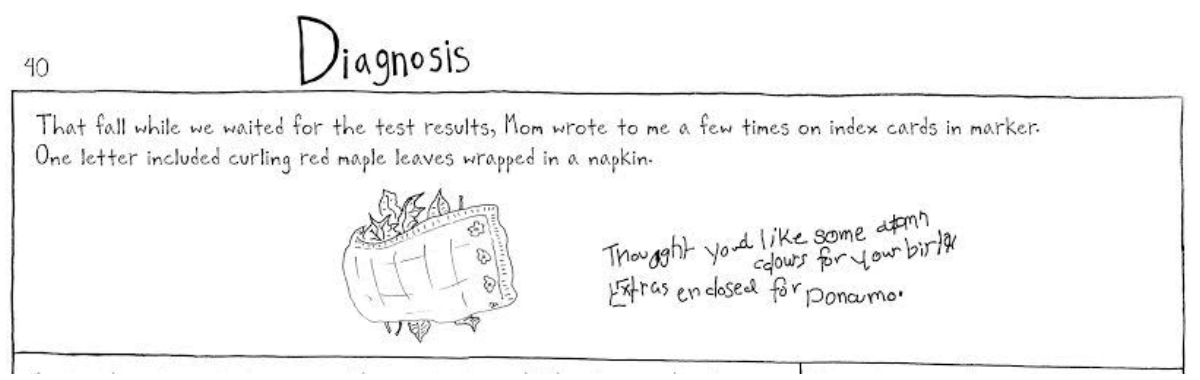

Figure 5. Image from Tangles: A Story About Alzheimer's, My Mother, and Me. (Leavitt, 2012, p. 40).

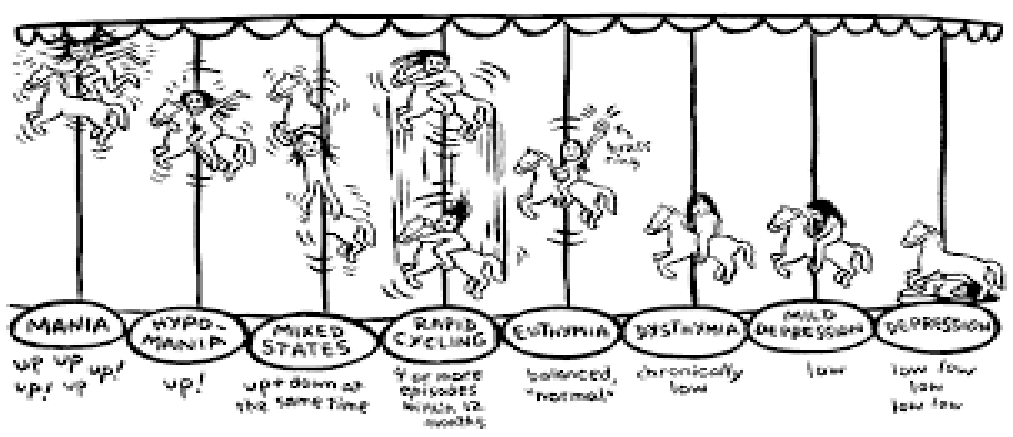

Figure 6. From Marbles: Mania, Depression, Michelangelo, and Me: A Graphic Memoir (Forney, 2012, p. 59).

\section{Eloquence of Visual Expression: Economy}

Yet another feature of comics is its economy of expression which aids readers to comprehend the intricacies of illness more lucidly than a written text. As comics spatializes time it also has the potential to narrate life stories in a succinct manner. Randy Duncan refers to "reductive devices" (2015, p. 112) such as synecdoche, metonymy, symbols and sequence metaphors as various means to accomplish economy in comics. When these devices function to generate a distinct meaning from juxtaposed images or parts of it, they economise the comics page and add eloquence to its expression. For instance, in Ellen Forney's Marbles: Mania, Depression, Michelangelo, and Me 
(2012) the memoirist depicts her bipolar disorder through the visual iconography of her riding a carousel horse in a single panel (see fig. 6). Here the image poignantly captures the sufferer's varying mood as a ride on a carousel-thus, in the manic state, she is at a great height balancing on the horse's back with one leg; in the depressed condition, she slides down from her horse and is curled up on the floor. Although such an emotional shift would mean a week or a month in real time, Forney encapsulates her particular mental state of bipolar disorder in a single panel.

Similarly, Fies modulates colour, focus, and panel size to illustrate his mom's absence seizure and its effect on her daughter (see fig. 7). From the first panel, the background of the panel and other features alter as mom assumes a static pose. While mom's eye colour changes from black to white as someone experiencing a slip from consciousness, the background colour shifts across shades of grey to black and the panel size contracts to foreground mom's blank expression. The effect of seizure and the anxiety and fear that grips her daughter is commendably economised in these accordion like panels.
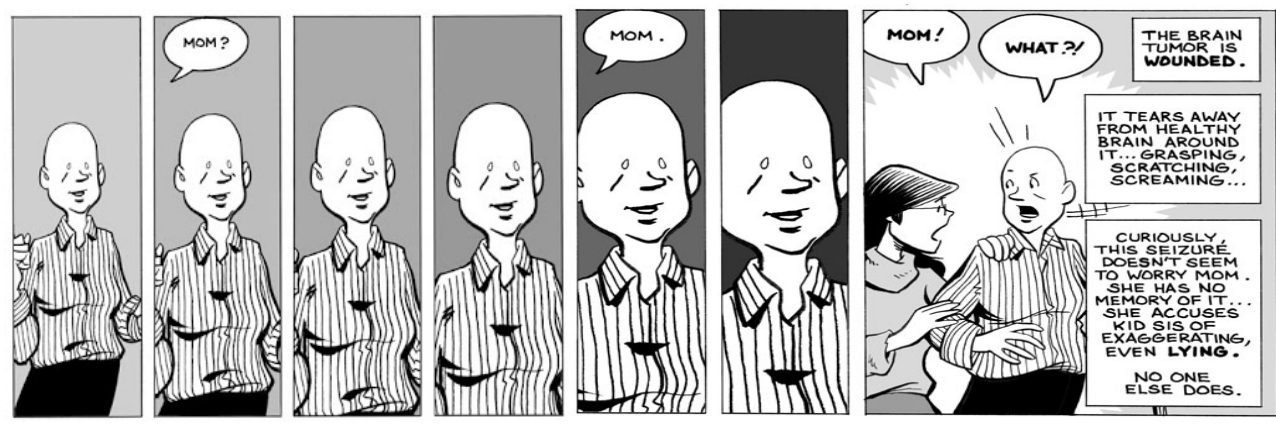

Figure 7. Panels depicting Mom's absence seizure (Fies, 20o6, p. 69, 70).

\section{Implications of Comics Affordances in Graphic Medicine}

Confirming the potency of comics as opposed to the verbal language, Green asserts thus, "comics can give voice to the unsettling worries and concerns that may be difficult to articulate through words alone" (2015, p. 774). The affordances unique to the medium of comics provide multiple ways for the artists' to combine "subjective feelings and perceptions with the objective visual representation" (Czerweic, 2015, p. 19). Although comics establishes and accomplishes a performative and vital relationship among all its attributes within a diegetic space, it is possible to delineate their functional/rhetorical role on a technical and conceptual level. Accordingly, if the spatio-temporal aspect enhances the efficacy of the medium to map the fragmented illness experiences then gestures and economy evoke affective response in the reader. In a different way, gestures make comics more dynamic through its realistic relaying of human emotions while handwriting reveals interiority and emotional state of the artist. Put differently, the exhaustiveness of all these attributes makes comics highly expressive, economic yet succinct and an ideal medium to represent illness experience.

To conclude, comics is a befitting medium for the cogent encapsulation and translation of trauma/illness into "imagetexts" in that the affordances of the medium such as temporality, spatiality, gestures, handwriting and economy of expression capacitate graphic pathographers to articulate emotional accounts of subjective illness experiences and their attendant phenomenological truths. While visibilizing the intricate intrapsychic experiences of illness, these affordances also allow a unique reincarnation of the author into the intradiagetic realms of the narrative through embodiment. In essence, the structural singularity and formal affordances of 
the comics medium not only extend ingress into the subjective realities of sufferers but also actualize the otherwise ineffable intricacies of human lives.

\section{Notes}

i. The website graphicmedicine.org launched and curated by Ian Williams deepened this interdisciplinary field. Other prominent practitioners of graphic medicine include Susan Squier, MK Czerwiec, Michael Green, and Kimberly Myers.

ii. "Expressive anatomy" is borrowed from Will Eisner's book titled Expressive Anatomy for Comics and Narrative (2008).

\section{Works Cited}

Attardo, S. (2005). The Role of Affordances at the Semantic/Pragmatics Boundary. In B.G Bara , L. Barsalou and M. Bucciarelli (Eds.), Proceedings of the CogSci 2005: XXVII Annual Conference of the Cognitive Science Society (pp. 169-174). NJ: Lawrence Erlbaum.

Bredehoft, T. A. (2006). Comics Architecture, Multidimensionality, and Time: Chris Ware's Jimmy Corrigan: The Smartest Kid on Earth. MFS Modern Fiction Studies, 52(4), 869-890.

Berninger, M., Ecke, J., \& Haberkorn, G. (2010). Comics as a Nexus of Cultures: Essays on the Interplay of Media, Disciplines and International Perspectives. Jefferson, N.C: McFarland.

Chaney, M. A. (2011). Graphic subjects: Critical essays on autobiography and graphic novels. Madison, Wis: University of Wisconsin Press.

Chute, H. L and Marianne D. (2006). Introduction: Graphic Narrative. MFS Modern Fiction Studies, 52(4), 767-782.

Chute, H. L. (2010). Graphic Women: Life Narrative and Contemporary Comics. Columbia University Press.

Cour, E.L. (2010). Representation of Truth and Trauma in Personal Narrative: The Insight of Graphic Novels. Frame 23(1), 41-55.

Czerwiec, M K.(2015). Graphic Medicine Manifesto. Pennsylvania: The Pennsylvania State UP.

Drucker, J. (2008). What is Graphic About Graphic Novels. English Language Notes. 46(2), 39-55.

Duncan, R. (2015). The Power of Comics: History, Form and Culture. $2^{\text {nd }}$ ed. New York: Bloomsbury.

Eisner, W. (2008). Comics and Sequential Art: Principles and Practices from the Legendary Cartoonist. New York: W.W. Norton.

El, Refaie E. (2012). Autobiographical Comics: Life Writing in Pictures. Jackson: University Press of Mississippi.

Fies, B. (2006). Mom’s Cancer. New York: Abrams Image.

Forney, E. (2012). Marbles: Mania, Depression, Michelangelo, and Me: A Graphic Memoir. New York: Gotham Books.

Green, M. J, and Rieck R. (2013). Missed It. Annals of Internal Medicine. 158(5), $\quad$ 357-361.

Green, M. J (2015). Comics and Medicine: Peering Into the Process of Professional Identity Formation. Academic Medicine. 90 (6), 774-9. 
Hawkins, A. H. (1999). Introduction. Reconstructing Illness: Studies in Pathography. West Lafayette: Purdue UP.

Hirsch, M. (2004). Editor's Column: Collateral Damage. PMLA 119(5), 1209-1215.

Leavitt, S. (2012). Tangles: A Story About Alzheimer's, My Mother, and Me. New York: Skyhorse Publishing.

Lefevre, P. (2011). Some Medium-Specific Qualities of Graphic Sequences. Substance. 40(1), 14-33.

Marchetto, M. A. (2006). Cancer Vixen: A True Story. New York: Alfred A. Knopf.

McCloud, S. (1994). Understanding Comics: The Invisible Art. New York: HarperPerennial.

McCloud, S. (April 2007). Scott McCloud/ Interviewer: Hillary Chute. The Believer Fall 2015.

Miller, N. K. (2014). The Trauma of Diagnosis: Picturing Cancer in Graphic Memoir. Configurations. 22(2), 207-223.

Quesenberry, K and Squier, S. M., (2016). Life Writing and Graphic Narratives. Life Writing. 13(1), 63-85.

Ramanathan, V. (2009). Texting Dopplegangers: Repitition, Signs, and Intentionalities in (Auto)biographical Alzheimer Writing. Journal of Literary \& Cultural Studies. 3(1), 67-84.

Scarry, E. (1985). The Body in Pain: The Making and Unmaking of the World. New York: Oxford UP.

Spiegelman, A. (2005). Ephemera vs. the Apocalypse. Indy Magazine. Autumn 2005. Retrieved from http://64.23.98.142/indy/autumn_2004/spiegelman_ephemera/index.html.

Squier, S. M. (2008). Literature, and Medicine, Future Tense: Making it Graphic. Literature and Medicine. $27(2), 124-154$.

Squier, S. M. (2005). The Uses of Graphic Medicine for Engaged Scholarship. In MK Czerwiec (Ed.), Graphic Medicine Manifesto. Pennsylvania: The Pennsylvania State UP.

Streeten, N. (2011). Billy, me E you: A memoir of grief and recovery. Brighton, England: Myriad.

Versluys, K. (2006). Art Spiegelman's In the Shadow of No Towers: 9-11 and the Representation of Trauma. MFS Modern Fiction Studies. 52(4), 980-1003.

Venkatesan, Sathyaraj. (2016). "Graphic Medicine Manifesto, by M. K. Czerwiec, Ian

Williams, Susan Merrill Squier, Michael J. Green, Kimberly R. Myers, and Scott T. Smith." Journal of Graphic Novels and Comics. 7(1): 93-94.

Williams, I C M. (2012). Graphic Medicine: Comics as Medical Narrative. MedHumanities. 38(1), $21-27$.

Willig, C. (2009). 'Unlike a Rock, a Tree, a Horse, or an Angel. . .': Reflections on the Struggle for Meaning through Writing during the Process of Cancer Diagnosis. Journal of Health Psychology. 14(2), 181-189. 